\title{
SISTEM PENUNJANG KEPUTUSAN PEMILIHAN INDUK AYAM KUB TERBAIK DENGAN METODE FUZZY DAN VIKOR
}

\author{
Muhammad Teguh'), Sri Setyaningsih'), Mulyati ${ }^{3)}$ \\ ${ }^{123) P r o g r a m ~ S t u d i ~ I I m u ~ K o m p u t e r, ~ F M I P A, ~ U n i v e r s i t a s ~ P a k u a n, ~ B o g o r, ~ I n d o n e s i a ~}$ \\ ${ }^{3)}$ Corresponding Author: mulyati@unpak.ac.id
}

Article history: received 11 December 2019; revised 16 January 2020; accepted 23 January 2020

\begin{abstract}
Abstrak
Ayam Kampung Unggul Balitbang (KUB) merupakan ayam kampung asli seleksi dari Balai Penelitian Ternak (Balitnak). Ayam KUB memiliki keunggulan yaitu mengeram rendah dan produksi telur tinggi, sehingga menjadi indukan penghasil DOC (female line) yang banyak. Saat ini Konsumsi daging dan telur ayam kampung di masyarakat dari tahun ketahun mengalami peningkatan sedangkan produksinya belum mampu sepenuhnya memenuhi kebutuhan masyarakat. Beberapa Permasalahan dalam memelihara induk Ayam KUB yaitu tidak optimalnya berat badan, lamanya dalam bertelur dan kualitas produksi telur yang dihasilkan sedikit sekalipun itu dari calon induk yang di pilih berasal dari Ayam KUB yang memiliki produktifitas tinggi dalam bertelur. untuk mengatasi permasalahan tersebut diperlukan adanya sebuah sistem aplikasi salah satunya adalah aplikasi sistem pendukung keputusan. Aplikasi ini dapat memberikan rekomendasi dalam pemilihan induk Ayam KUB terbaik sehingga induk ayam tersebut dapat dipelihara secara intensif agar penyediaan daging dan telur ayam dapat mencukupi kebutuhan masyarakat. Ada beberapa metode yang dapat digunakan untuk menentukan pemilihan Induk Ayam KUB terbaik diantaranya yaitu dengan menggunakan metode Vikor. Vikor digunakan untuk mengatasi permasalahan multikriteria sistem yang kompleks yang berfokus pada ranking dan seleksi dari sebuah alternatif, sedangkan untuk menentukan pembobotan menggunakan Metode Fuzzy. Adapun hasil penelitian ini berupa sebuah sistem aplikasi yang dapat membantu para peternak/Teknisi Kandang dalam menentukan pemilihan Induk Ayam KUB Terbaik. Tingkat akurasi sistem dengan menggunakan metode Vikor dan Fuzzy diperoleh sebesar 77,2\% dari 9 data uji yang digunakan.
\end{abstract}

Kata kunci: ayam KUB, fuzzy tahani, sistem pendukung keputusa, vikor

\begin{abstract}
Kampung Unggul Superior Chicken (KUB) is a native native chicken selection from the Animal Research Center (Balitnak). KUB chicken has the advantage of low incubation and high egg production, so it becomes a parent producer of many DOC (female line). Currently consumption of native chicken meat and eggs in the community from year to year has increased while its production has not been able to fully meet the needs of the community. Some of the problems in maintaining KUB hens are not optimal body weight, length of time in laying eggs and even a small amount of egg production quality from selected prospective broodies originating from KUB hens who have high productivity in laying eggs. to overcome these problems, an application system is needed, one of which is a decision support system application. This application can provide recommendations in the selection of the best KUB hens so that the hens can be maintained intensively so that the supply of chicken meat and eggs can meet the needs of the community. There are several methods that can be used to determine the selection of the best KUB Parent, including using the Vikor method. Vikor is used to overcome the problem of complex multi-criteria systems that focus on ranking and selection of an alternative, while to determine the weighting using the Fuzzy Method. The results of this study are in the form of an application system that can help breeders / enclosure technicians in determining the selection of the Best KUB Chicken Parent. The level of system accuracy using the Vikor and Fuzzy methods was obtained at $77.2 \%$ of the 9 test data used.
\end{abstract}


Keywords: KUB chicken, fuzzy tahani, keputusa support system, vikor

\section{Pendahuluan}

Ayam Kampung Unggul Balitbang (KUB) merupakan ayam kampung asli seleksi dari Balai Penelitian Ternak (Balitnak). Budidaya Ayam Kampung Unggul Balitbang (KUB) bertujuan untuk meningkatkan produksi telur ayam kampung agar mampu memenuhi kebutuhan masyarakat. Ayam Kampung Unggul Balitbang (KUB) memiliki keunggulan seperti sifat mengeram rendah dan produksi telur tinggi, sehingga menjadi indukan penghasil DOC (female line) yang banyak, Saat ini daging ayam menjadi pemasok daging nasional terbesar, di atas produksi daging sapi[1]. Konsumsi daging dan telur ayam kampung di masyarakat dari tahun ketahun mengalami peningkatan sedangkan produksinya belum mampu sepenuhnya memenuhi kebutuhan masyarakat. Untuk itu perlu dilakukan pemeliharaan ayam secara intensif agar penyediaan daging dan telur ayam dapat mencukupi kebutuhan masyarakat. Ada beberapa masalah dalam memelihara induk Ayam Kampung Unggul Balitbang (KUB) yaitu tidak optimalnya berat badan, lamanya dalam bertelur dan kualitas produksi telur yang dihasilkan sedikit sekalipun itu dari calon induk yang di pilih berasal dari Ayam KUB yang memiliki produktifitas tinggi dalam bertelur. Untuk mengatasi permalsahan tersebut diperlukan aplikasi sistem pendukung keputusan untuk memilih induk Ayam KUB terbaik dimana ayam tersebut memiliki frekuensi bertelur yang banyak, berat badan yang baik, dan cepat bertelur. Beberapa metode yang dapat digunakan dalam pemilihan ayam terbaik salah satunya adalah metode Vikor. Vikor digunakan untuk mengatasi permasalahan multikriteria sistem yang kompleks yang berfokus pada ranking dan seleksi dari sebuah alternative. Beberapa penelitian yang pernah dilakukan dengan menggunakan Vikor diantaranya dalam pemilihan robot industri pada aplikasi teknik [2], pemilihan bahan Biomedis [3], pemilihan penerima beasiswa [4], penentuan jenis kulit terbaik untuk pembuatan sepatu [5], pemilihan Calon Peserta Olimpiade Olahraga Siswa Nasional (O2SN) [6], Rekomendasi Pembelian Mobil bekas [7], Penentuan bahan kulit terbaik dalam pembuatan ikat pinggang [8], penentuan penerimaan Bonus pada Salesman Indihome [9], dan rekomendasi pemilihan TV LED terbaik [10]. Dari beberapa penelitian tersebut, menunjukkan bahwa Metode Vikor mempunyai kemampuang dalam perangkingan dan dapat mengompromi alternatif yang ada sehingga memudahkan pembuat keputusan dalam mengambil keputusan.

Sedangkan untuk menentukan pembobotan atribut menggunakan metode fuzzy. Penentuan Pembobotan ini sangat berguna untuk mendapatkan solusi dalam metode Vikor. Penentuan pembobotan dengan metode fuzzy pernah dilakukan oleh Nurmahaludin [11]. Metode ini dipilih karena dapat menentukan nilai bobot untuk setiap atribut yang akan menyeleksi alternatif "Baik" dari sejumlah alternatif lainnya, Dengan metode tersebut penilaian akan lebih akurat dan memiliki toleransi terhadap data yang tidak tepat atau data yang bersifat fuzy/kabur.

\section{Metode Penelitian}

Metodologi Penelitian dalam Sistem Pendukung Keputusan Pemilihan Induk Ayam KUB terbaik dengan metode Fuzzy dan Vikor adalah pola sisklus hidup pengembangan sistem/System Development Life Cycle (SDLC). Tahap-tahap pendekatan SDLC secara lengkap di sajikan pada Gambar 1. 


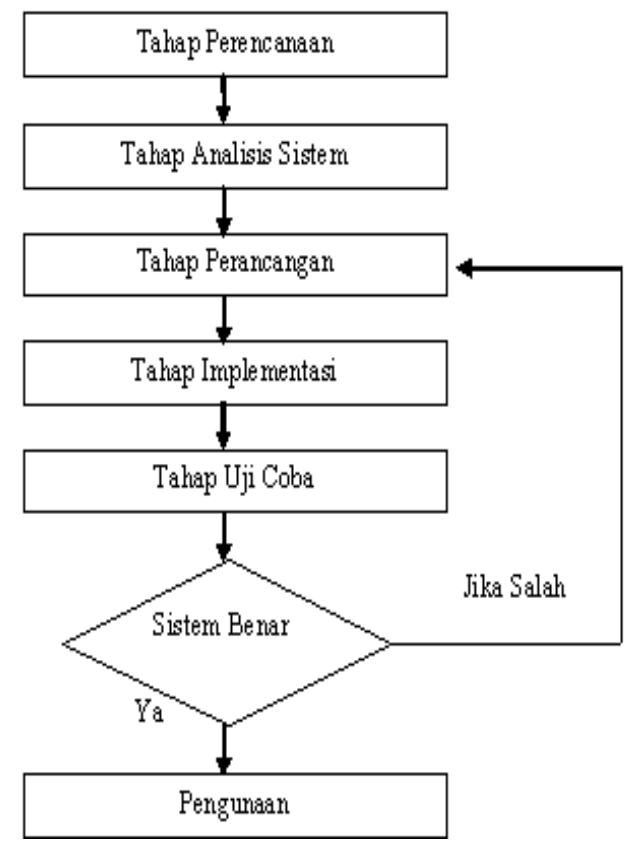

Gambar 1 Diagram Tahapan SDLC

\subsection{Perencanaan sistem}

Tahap perencanaan sistem dilakukan dengan melakukan studi kelayakan, meliputi : teknik penjadwalan, pengumpulan data ayam, pemilihan metode dan konsep yang akan di tampilkan pada aplikasi pemilihan induk ayam KUB.

\subsection{Analisis Sistem}

Tahap analisis ini dilakukan dengan proses pengumpulan, penyeleksian, pengolahan serta perancangan data yang sebelumnya sudah didapat dari tahap perencanaan sistem. Data tersebut kemudian dibentuk dan diolah sehingga terbentuk suatu sistem yang dapat memilih Induk ayam KUB terbaik dengan menggunakan Fuzzy dan Vikor.

\subsection{Perancangan Sistem}

Tahap perancangan dilakukan guna memudahkan tahapan berikutnya yakni tahap implementasi. Tahap perancangan sistem dimulai dengan pembuatan database mencakup Entity Relationship Diagram (ERD), rancangan flowchart sistem, dan rancangan antar muka sesuai dengan tujuan penelitian.

\subsection{Implementasi Sistem}

Pada tahap implementasi sistem ini, dibuatlah aplikasi sistem Rekomendasi pemilihan induk ayam KUB terbaik. Adapun tahapannya adalah sebagai berikut:

1. Implementasi basis data

Pembuatan basis data atau database menggunakan MySQL XAMPP, yang berisi tabel-tabel yang saling berhubungan satu dengan lainnya.

2. Implementasi pembuatan aplikasi

Pada tahap ini, aplikasi digunakan menggunakan bahasa pemograman PHP yang ditulis pada Sublime Text.

\subsection{Uji Coba (Testing)}

Tahap uji coba ini dilakukan untuk memastikan apakah hasil dari sistem sesuai dengan hasil sebenarnya. Tahap-tahap pengujian yang dilakukan adalah : 
a. Uji Struktural

Uji coba untuk mengetahui apakah sistem telah terstruktur dengan baik yang ditekankan pada fitur-fitur aplikasi yang memenuhi kebutuhan pengguna apakah sudah baik dan benar sesuai dengan rancangan yang telah dibuat.

b. Uji Fungsional

Uji coba fungsional dilakukan untuk mengetahui proses navigasi dan validasi apakah aplikasi yang dibuat dapat berfungsi dengan baik atau tidak sesuai dengan fungsinya.

c. Uji Validasi

Uji coba validasi dilakukan dengan uji coba data dan hasilnya, apakah hasil dari sistem sesuai dengan hasil yang diharapkan.

\subsection{Penggunaan Sistem}

Tahap penggunaan sistem dilakukakan apabila aplikasi yang telah dibuat berjalan atau bekerja sebagaimana mestinya dan sesuai dengan apa yang diinginkan. Sistem yang dibuat untuk mempermudah para peternak untuk mencari Induk ayam KUB terbaik.

\section{Hasil dan Pembahasan}

Tampilan hasil perancangan pada Sistem penunjang keputusan untuk pemilihan ayam KUB terbaik dengan menggunakan metode fuzzy dan Vikor diperoleh sebagai berikut.

\subsection{Halaman Beranda}

Pada halaman Beranda terdapat sejarah Balitnak. Terdapat juga pilihan beberapa menu. Gambar 2 adalah tampilan Beranda atau halaman utama.

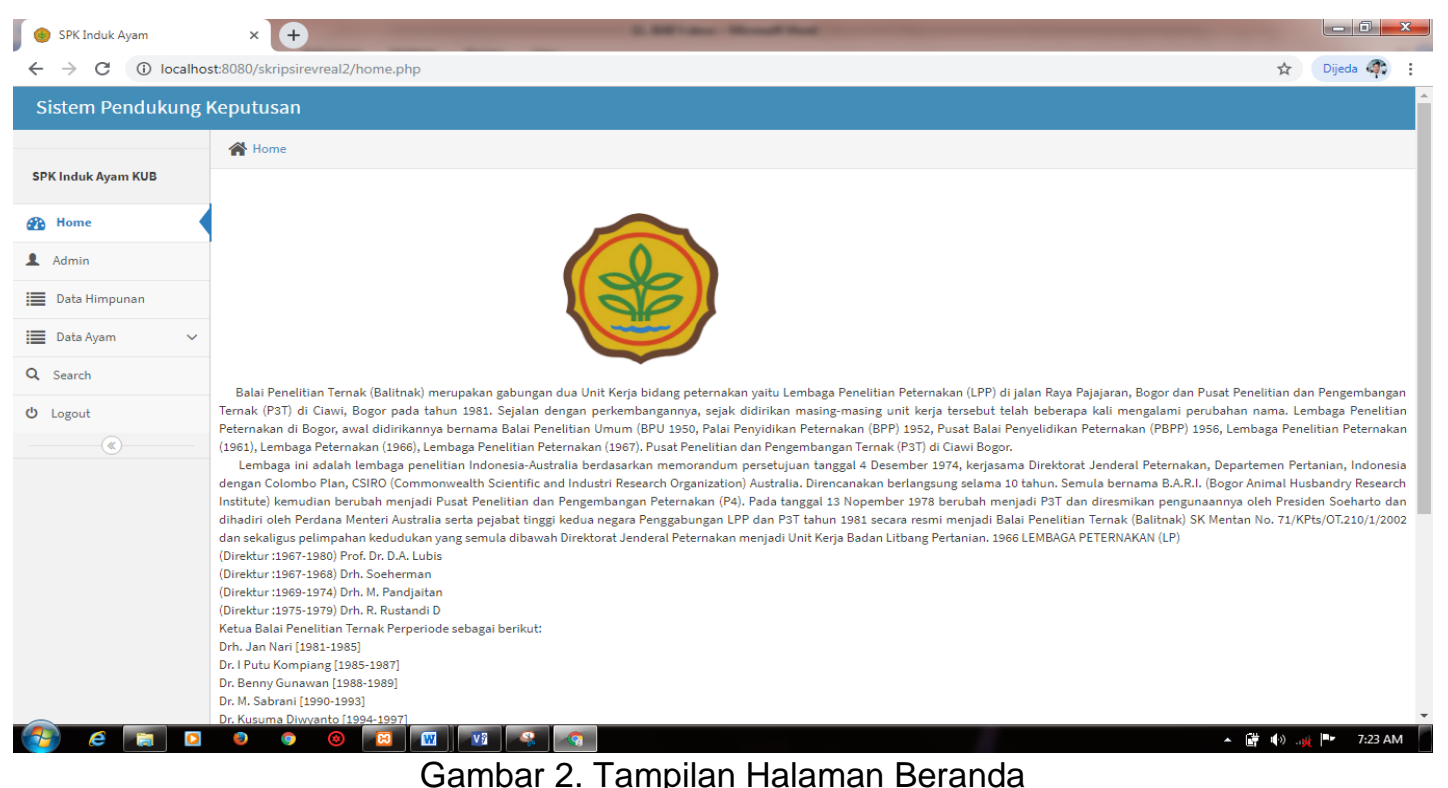

\subsection{Halaman Data Himpunan}

Gambar 2. Tampilan Halaman Beranda

Halaman Data Himpunan merupakan untuk mengubah nilai min-max interval dan bobot setiap kriteria pada data Induk Ayam KUB. Gambar 3 adalah tampilan Data Himpunan. 
KOMPUTASI (Jurnal IImiah IImu Komputer dan Matematika)

Vol. 17, No. 1, Januari 2020, Hal. $339-345$

P-ISSN: 1693-7554, E-ISSN: 2654-3990

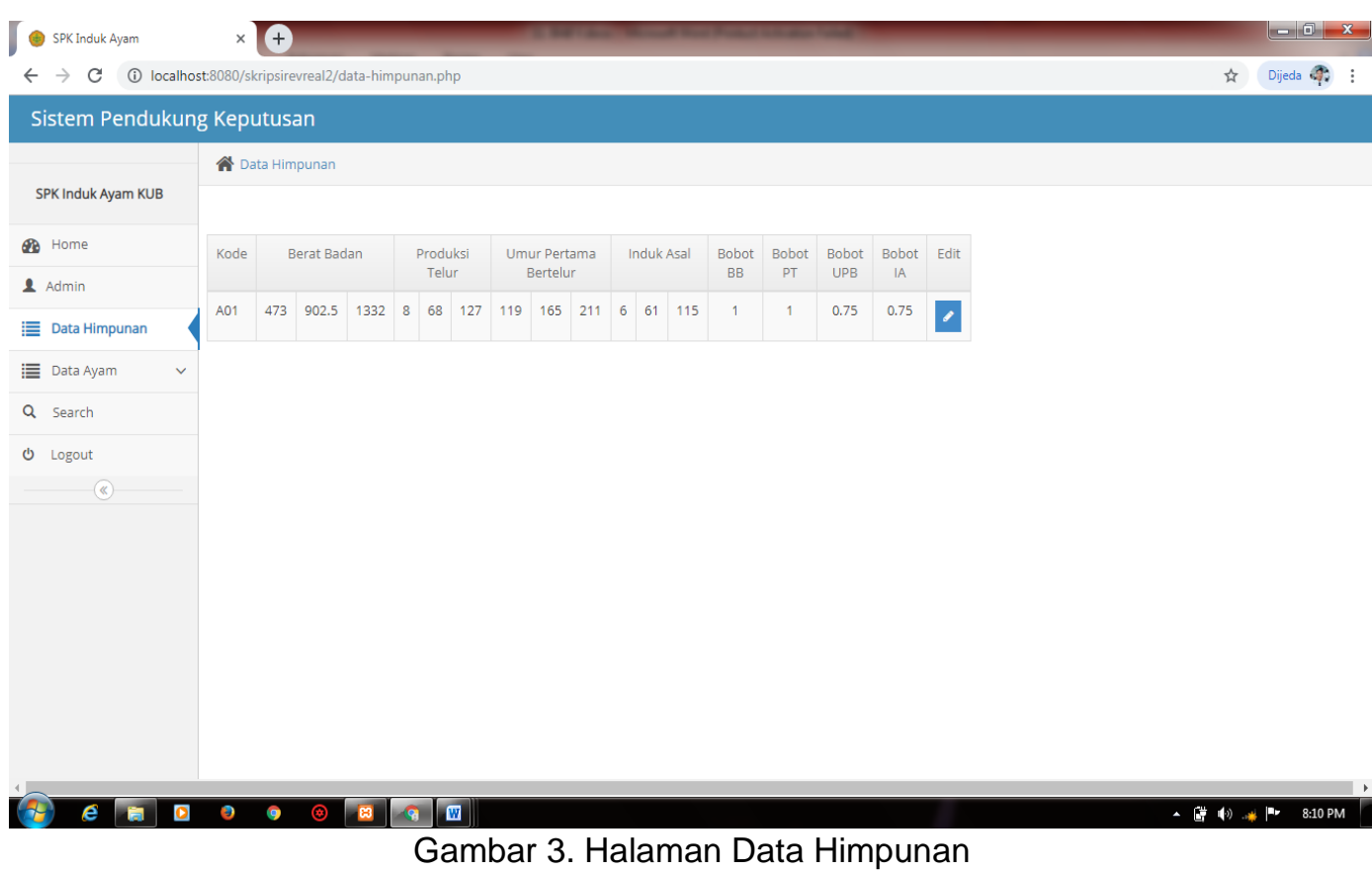

\subsection{Halaman Data Induk Ayam KUB}

Halaman data induk ayam KUB digunakan oleh admin/teknisi kandang seperti pada Gambar 4 merupakan halaman yang mengelola data ayam KUB. Dalam halaman data Ayam KUB dapat mengelola data dengan menambah, mengedit dan hapus. Dengan mengisi data Induk Ayam KUB tersebut kemudian di perhitungkan menggunakan Metode Fuzzy dan VIKOR.

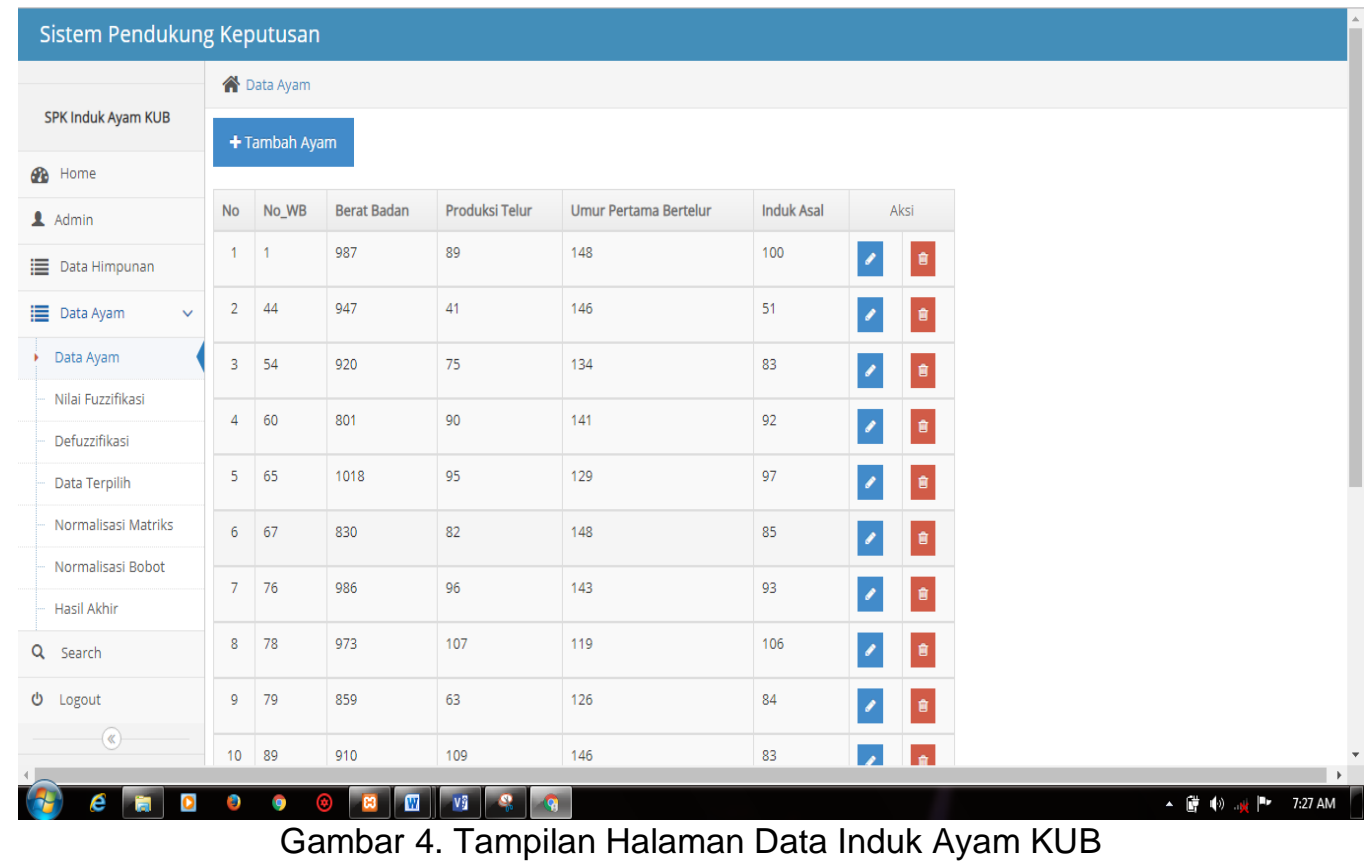

\subsection{Halaman Induk Ayam Baik Kurang}

Pada halaman Defuzzifikasi menghasilkan bahwa data induk Ayam KUB yang dinyatakan Baik hanya ada 9 Induk ayam, dari 15 data induk ayam yang digunakan, 9 data induk ayam yang dinyatakan Baik di seleksi lagi untuk mencari yang terbaik dengan metode Vikor. Grafik Defuzzifikasi dapat dilihat pada Gambar 5. 


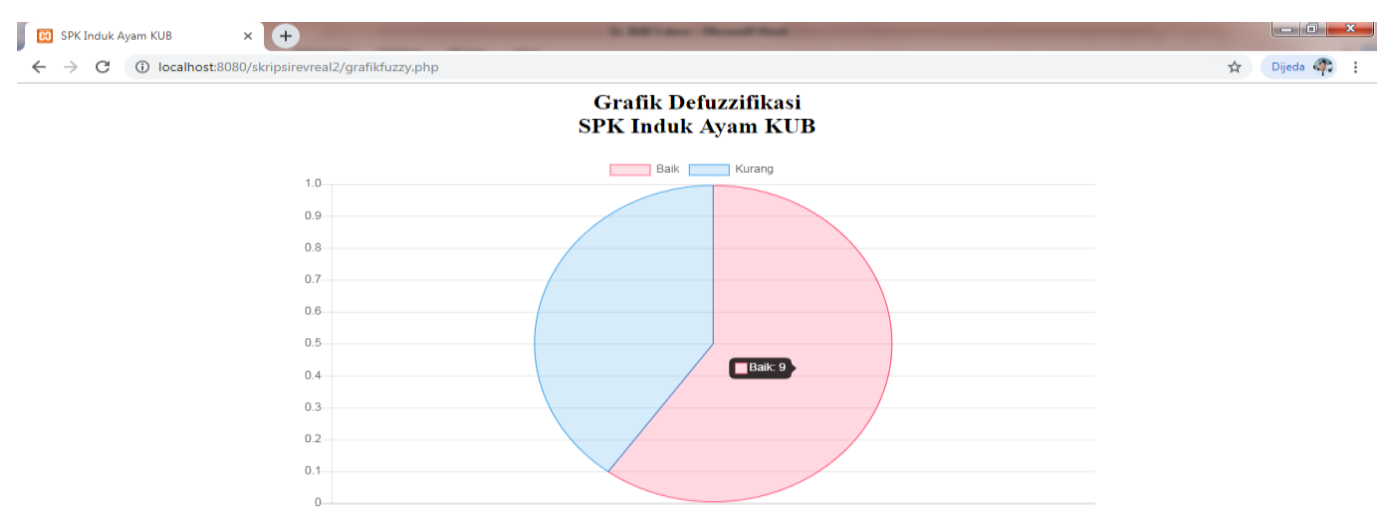

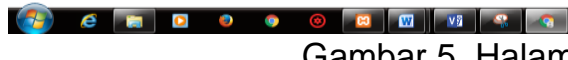

Gambar 5. Halaman Induk Ayam Baik dan Kurang

\subsection{Halaman Induk Ayam Perankingan}

Pada Halaman data ayam menghasilkan keputusan perankingan, dari nilai terkecil sampai terbesar, nilai terkecil yang menunjukan kualitas yang lebih baik dari Alternatif yang lainnya, Induk Ayam KUB yang terbaik pada no wb 98 dengan berat badan 1103 gram, menghasilkan 101 butir telur, umur pertama bertelur memerlukan waktu hanya 146 hari dan Induk Asalnya menghasilkan 110 butir telur. Gambar 6 merupakan tampilan Hasil Perangkingan.

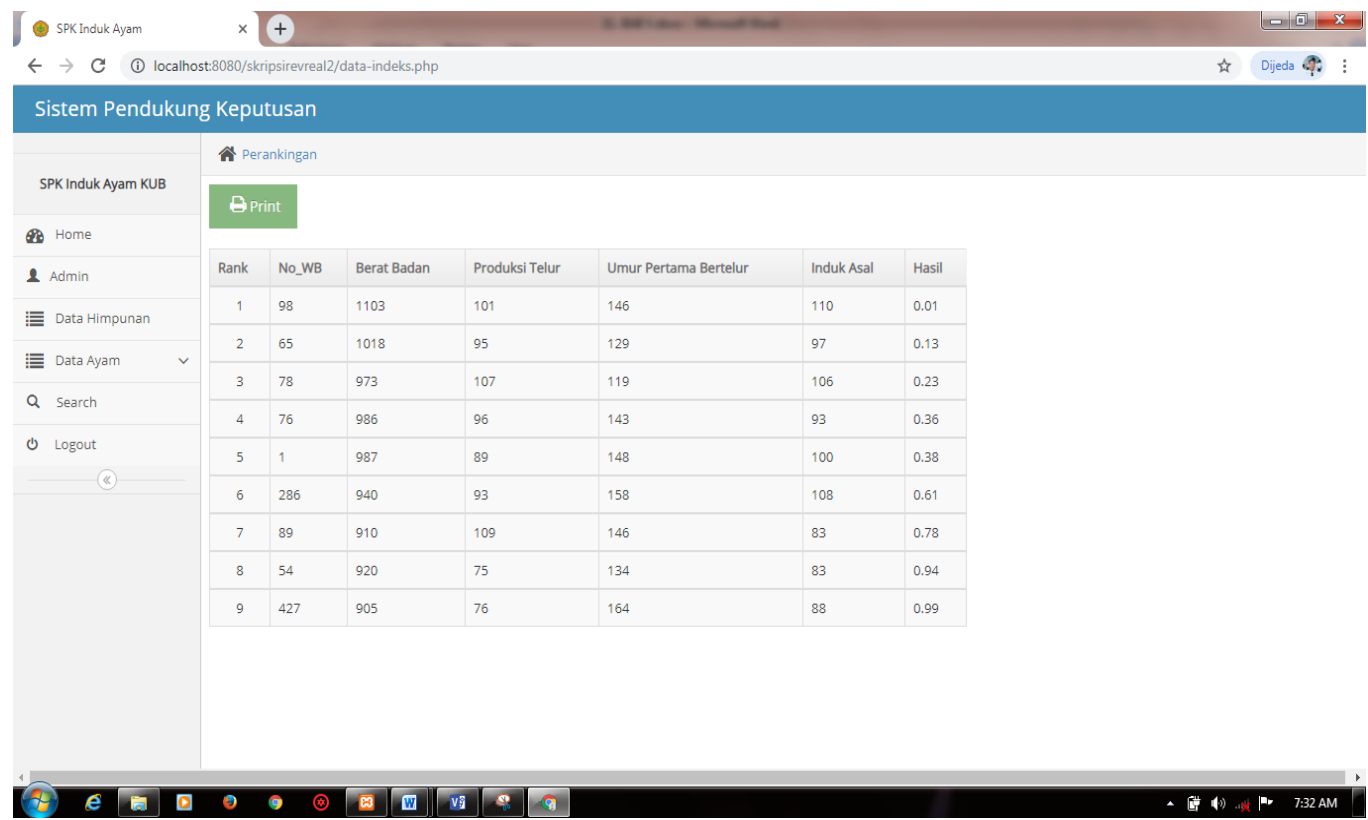

\subsection{Hasil Pengujian sistem}

Gambar 6. Halaman Induk Ayam Hasil Perankingan

Pengujian sistem yang dilakukan dengan cara membandingkan hasil dari balai penelitian ternak dengan hasil sistem dapat dilihat pada Tabel 12. Berdasarkan tabel tersebut, terdapat hasil perankingan Induk Ayam KUB Terbaik yang sesuai dari hasil di balitnak dengan hasil di sistem. menunjukan No WB 95 yang menjadi Induk Ayam KUB Terbaik dan dari 9 data uji yang digunakan hanya 2 data yang tidak sesuai. Nilai akurasi sistem diperoleh sebesar $77,8 \%$. Hal ini dapat disimpulkan bahwa metode Fuzzy dan Vikor dapat diimplementasikan untuk pemilihan induk ayam KUB Terbaik. 
KOMPUTASI (Jurnal IImiah IImu Komputer dan Matematika)

Vol. 17, No. 1, Januari 2020, Hal. $339-345$

P-ISSN: 1693-7554, E-ISSN: 2654-3990

https://journal.unpak.ac.id/index.php/komputasi

Tabel 1. Perbandingan Hasil di Balitnak dengan Hasil di Sistem

\begin{tabular}{llllllll}
\hline Rank & $\begin{array}{l}\text { Berat } \\
\text { Badan }\end{array}$ & $\begin{array}{l}\text { Produksi } \\
\text { Telur }\end{array}$ & UPB & $\begin{array}{l}\text { Induk } \\
\text { Asal }\end{array}$ & $\begin{array}{l}\text { Hasil } \\
\text { Balitnak } \\
\text { No WB }\end{array}$ & $\begin{array}{l}\text { Hasil } \\
\text { Sistem } \\
\text { No WB }\end{array}$ & Validasi \\
\hline 1 & 1103 & 101 & 146 & 110 & 98 & 98 & Sesuai \\
\hline 2 & 973 & 107 & 119 & 106 & 78 & 65 & Tidak \\
\hline 3 & 1018 & 95 & 129 & 97 & 65 & 78 & Tidak \\
\hline 4 & 986 & 96 & 143 & 93 & 76 & 76 & Sesuai \\
\hline 5 & 987 & 89 & 148 & 100 & 1 & 1 & Sesuai \\
\hline 6 & 940 & 93 & 158 & 108 & 286 & 286 & Sesuai \\
\hline 7 & 910 & 109 & 146 & 83 & 89 & 89 & Sesuai \\
\hline 8 & 920 & 75 & 134 & 83 & 54 & 54 & Sesuai \\
\hline 9 & 905 & 76 & 164 & 88 & 427 & 427 & Sesuai \\
\hline
\end{tabular}

\section{Kesimpulan}

Adapun Kesimpulan yang diperoleh dari hasil perancangan sistem Pendukung Keputusan Pemilihan Induk Ayam KUB Terbaik adalah Sistem Penunjang Keputusan dalam pemilihan ayam KUB terbaik dengan Metode Fuzzy dan Vikor dapat digunakan untuk para teknisi/peternak dalam memilih ayam KUB terbaik. Kemudian, hasil pengujian diperoleh nilai akurasi sebesar $77,8 \%$ dari 9 data yang diuji dengan cara membandingkan hasil di sistem dengan hasil dari balas Penelitian Ternak Bogor.

\section{References}

[1]. Jojo. 2019. Jalan Muram Swasembada Daging. https://kolom.tempo.co/. Diakses 12 Januari 2020.

[2] Chatterjee P, Athawale VM, Crakraborty S. 2010. Selection of industrial robots using compromise ranking and outranking methods. Robotics and Computer Integrated Manufacturing 26(5): 483-489.

[3] Jahan A, Mustapha F, Ismail MY, Sapuan SM, Bahraminasab. 2011. A comprehensive VIKOR method for material selection. Materials and Design. 32: 1215-1221.

[4] Hutapea BJ, Hasmi MA, Karim A, Suginam. 2018. Sistem Pendukung Keputusan Penentuan Jenis Kulit Terbaik Untuk Pembuatan Sepatu dengan Menggunakan Metode VIKOR. Jurnal Riset Komputer (JURIKOM). 5(1): 6-12.

[5] Suwardika G, Suniantara PIK. 2018. Penerapan Metode VIKOR pada Pengambilan Keputusan Seleksi Calon Penerima Beasiswa Bidikmisi Universitas Terbuka. Jurnal IImiah Penelitian dan Penerapan Teknologi Sistem Informasi. 2(1): 24-35.

[6] Muhammad WP. Agatmadja, Suri A, Agustin. 2018. Penerapan metode VIKOR dalam Pemilihan Calon Peserta Olimpiade Olahraga Siswa Nasional (O2SN). Jurnal Riset Komputer (JURIKOM). 5(2): 91-96.

[7] Nababan DR, Lestari P, Rizka N. Sistem Pendukung Keputusan Pembelian Mobil Bekas dengan Menerapkan Metode VIKOR. Seminar Nasional Sains \& Teknologi Informasi (SENSASI). Medan. 2018: 552-559.

[8] Sianturi M, Wulan S, Suginam, Rohminatin, Mesran. 2018. Implementasi Metode VIKOR Untuk Menentukan Bahan Kulit Terbaik dalam Pembuatan Ikat Pinggang. Jurnal Riset Komputer (JURIKOM). 5(1): 56-60.

[9] Primadasa Y, Juliansa H. 2019. Penerapan Metode Vikor dalam Seleksi Penerimaan Bonus Pada Salesman Indihome. Jurnal Teknologi Informasi \& Komunikasi Digital Zone. 10(1):3343.

[10] Simamora B. 2017. Rancang Bangun Sistem Rekomendasi Televisi LED dengan Metode Vikor Berbasis Web. ULTIMATICS. 9(1):42-49.

[11] Nurmahaludin, Cahyono GR. 2015. Logika Fuzzy Dalam Penentuan Bobot Kriteria Pada Pemilihan Varietas Pada Unggul. Jurnal POROS TEKNIK. 7(2): 82-87. 